\title{
Long non-coding RNA GAS5 in human cancer (Review)
}

\author{
XIAOYAN YANG ${ }^{1-3}$, ZHIZHONG XIE $^{2,3}$, XIAOYONG LEI $^{2,3}$ and RUNLIANG GAN ${ }^{1}$ \\ ${ }^{1}$ Cancer Research Institute, Hengyang Medical College; ${ }^{2}$ Hunan Province Cooperative Innovation Center for Molecular Target \\ New Drug Study; ${ }^{3}$ Institute of Pharmacy and Pharmacology, University of South China, Hengyang, Hunan 421001, P.R. China
}

Received July 31, 2019; Accepted February 11, 2020

DOI: $10.3892 / \mathrm{ol} .2020 .11809$

\begin{abstract}
Long non-coding RNAs (lncRNAs) constitute a group of $>200$-nucleotide ncRNA molecules. IncRNAs regulate several cell functions, such as proliferation, apoptosis, invasion and metastasis. Meanwhile, lncRNAs are abnormally expressed in human malignancies, where they suppress or promote tumor growth. The present study focused on growth arrest-specific transcript 5 (GAS5), a well-known IncRNA that acts as a tumor suppressor but is suppressed in multiple types of cancer, including mammary carcinoma, prostate cancer, colorectal cancer, gastric cancer, melanoma, esophageal squamous cell carcinoma, lung cancer, ovarian cancer, cervical cancer, gliomas, osteosarcoma, pancreatic cancer, bladder cancer, kidney cancer, papillary thyroid carcinoma, neuroblastoma, endometrial cancer and liver cancer. Notably, GAS5 is overexpressed in liver cancer, potentially functioning as an oncogene. In the present study, the diagnostic and therapeutic roles of GAS5 in different tumors were reviewed, with a summary of the potential clinical application of the lncRNA, which may help identify novel study directions for GAS5.
\end{abstract}

\section{Contents}

1. Introduction

2. Research background of GAS5

3. GAS5 in various cancer types

4. Conclusions

Correspondence to: Professor Xiaoyong Lei, Institute of Pharmacy and Pharmacology, University of South China, 28 Western Changsheng Road, Hengyang, Hunan 421001, P.R. China

E-mail: 1622214323@qq.com

Professor Runliang Gan, Cancer Research Institute, Hengyang Medical College, University of South China, 28 Western Changsheng Road, Hengyang, Hunan 421001, P.R. China

E-mail: ganrunliang@163.com

Key words: long non-coding RNA, GAS5, tumor suppressor gene, diagnostic biomarker, therapeutic targe

\section{Introduction}

As one of the deadliest diseases, cancer represents a growing clinical challenge worldwide (1), despite surgical, chemotherapeutic and radiotherapeutic advances $(2,3)$. A reason for the poor prognosis in cancer is the lack of efficient pre-progression diagnostic methods and effective prognostic indicators to guide clinical treatment. Therefore, it is important and necessary to identify suitable biomolecules for the timely detection of cancer to inform clinical decisions.

Long non-coding RNAs (lncRNAs) constitute a group of $>200$-nucleotide ncRNAs $(4,5)$. Due to the significant progress of sequencing technology witnessed in previous years, more and more lncRNAs are considered transcriptional noise and have been identified in the human genome (6-9). However, numerous studies have shown that lncRNAs contribute to human pathologies via regulation of downstream target effectors $(10,11)$. IncRNAs can upregulate or downregulate tumorigenic genes $(12,13)$. Pertinent to clinical practice, lncRNAs could serve as potential markers or therapeutic targets for developing diagnostic and therapeutic strategies in different types of human cancer $(14,15)$.

The lncRNA growth arrest-specific transcript 5 (GAS5) is a novel tumor-suppressor lncRNA, which is downregulated in mammary carcinoma, stomach cancer, lung carcinoma, prostate cancer and other malignant tumors (16-18). A summary of research progression regarding the value of GAS5 in the diagnosis and treatment of different types of cancer is provided in the present study. In addition, the published mechanisms by which GAS5 regulates genes involved in tumor genesis are explored and the potential clinical application of GAS5 is reviewed.

\section{Research background of GAS5}

GAS5 was initially described by a report screening for potential tumor-suppressors whose expression levels were increased during growth stagnation (19). GAS5 is located on chromosome 1q25, with $\sim 630$ nucleotides (20). It is a 5'-terminal oligopyrimidine RNA comprised of 12 non-conserved exons (21). GAS5 introns are transcribed into 10 box C/D small nucleolar RNA (snoRNA) molecules and 2 mature lncRNAs (GAS5a and GAS5b) $(21,22)$. Although GAS5 has a short open reading frame, it encodes no protein and functions as a snoRNA host gene (23). 
GAS5 biologically functions through its introns, which encode a number of snoRNAs (22). Although the exact functions of GAS5 remain unknown, it encodes several snoRNAs regulating ribosomal RNA synthesis (22). The transcription products of GAS5 are widely found in tissues, but show instability in actively dividing cells (24). The spliced GAS5 RNA expression is decreased in growing cells, but increased in the growth stagnation period (25). Mourtada-Maarabouni et al (25) initially investigated the bioactivity of GAS5 in human T cells and demonstrated that GAS5 overexpression induces apoptosis and decreases the number of cells in the S-stage, while the silencing of GAS5 leads to the opposite results. These findings suggested that GAS5 is necessary to inhibit the growth of T cells (25). Several studies have been performed to elucidate the function of GAS5 in cancer. Notably, GAS5 expression levels are downregulated in several human solid tumors and such aberrant expression is negatively associated with tumor size, disease stage and prognosis $(24,26,27)$. In addition, GAS5 has been shown to affect cell cycle progression and is essential for normal growth stagnation (28). High GAS5 expression levels inhibit cell cycle progression, whereas GAS5 suppression reduces apoptosis and promotes accelerated cell division $(29,30)$, which will be described in detail later in this review.

\section{GAS5 in various cancer types}

Evidence has revealed that GAS5 is abnormally expressed in various human malignancies (16-18). GAS5 expression levels are downregulated in numerous malignant tumors, suggesting that GAS5 may have anticancer activity. In addition, GAS5 overexpression contributes to growth inhibition in various tumor cell lines in vitro (16-18). In this section, findings regarding GAS5 expression, clinical significance in various types of human cancer (Tables I and II) and the modulatory mechanisms of GAS5 in malignant tumors are discussed (Fig. 1).

Breast cancer. In comparison with non-cancerous tissue samples, cancer tissue specimens exhibit markedly reduced GAS5 transcription levels (16). The decrease in GAS5 expression levels suggests a plausible function of GAS5 in tumorigenesis. GAS5 is commonly downregulated in breast cancer tissue samples and cells, and this downregulation is associated with a large tumor volume, advanced tumor lymph node metastasis and estrogen receptor negativity (31). GAS5 could be used as a microRNA (miR)-23a sponge, which promotes autophagy and enhances the formation of autophagosomes after GAS5 overexpression (31). GAS5 downregulates phosphatase and tensin homolog (PTEN) induced by lapatinib in SKBR-3/Tr cells, suggesting that GAS5 may be a plausible target for overcoming drug resistance in mammary carcinoma (32). The decrease in GAS5 expression levels attenuates the responses of breast cancer cells to apoptosis stimulation (32). Additionally, the degree of mammary carcinoma cell death is associated with the expression levels of GAS5, suggesting that GAS5 is associated with patient prognosis (33). GAS5 may negatively regulate miR-21 via the RNA-induced silencing complex (RISC) in breast cancer (33). It is hypothesized that miR-21 and GAS5 modulate each other.
Prostate cancer $(\mathrm{PCa})$. $\mathrm{PCa}$ is the second most prevalent cancer in men and the sixth leading cause of cancer-associated mortality in men in 2008 worldwide (34). Compared with normal prostate tissue or primary prostate cancer, metastatic prostate cancer cells show markedly reduced GAS5 expression levels (35). In addition, further studies have shown that high expression levels of GAS5 promote basal cell apoptosis of prostate cancer cells and enhance the effect of apoptosis stimulation $(36,37)$. High GAS5 expression levels enhance cancer cell death induced by UV-C irradiation and chemotherapeutic drugs, while GAS5 downregulation attenuates these effects. GAS5 binds to the corresponding region of androgen receptor and suppresses transcription of this receptor (38). Therefore, improving the expression levels of cellular GAS5 alongside the administration of chemotherapeutics could provide an improved strategy for treating advanced $\mathrm{PCa}$. Since androgen receptor is needed for the survival of prostate cancer cells, GAS5 downregulation may increase pro-survival signals via the androgen receptor pathway (39). The aforementioned findings indicate that GAS5 may have an antitumor function in human prostate cancer.

Colorectal cancer (CRC). CRC is one of the leading causes of cancer-associated mortality worldwide (40). GAS5 is specifically downregulated in CRC. The decrease in GAS5 expression levels is associated with advanced stage and lymph node metastasis in CRC (41). High expression levels of GAS5 suppress the proliferation of CRC cells and promote apoptosis (41). In addition, GAS5 downregulates miR-182-5p expression (41), while miR-182-5p upregulation abrogates the effects of GAS5 overexpression in CRC cells. Moreover, GAS5 upregulates FOXO3a in CRC cells (41). In another study, GAS5 was reported to inhibit cell division, inducing $G_{0} / G_{1}$ block and apoptosis, indicating that GAS5 could be considered as a potential therapeutic target in CRC (42). In summary, these data suggest that GAS5 contributes to the progression of CRC metastasis and may be used as a prognostic marker of CRC.

Gastric cancer $(G C)$. GC represents one of the deadliest malignancies worldwide (43). The etiological mechanism of gastric cancer remains unclear, but various environmental and genetic factors are considered to induce GC progression (44-46). In previous years, it has been demonstrated that GAS5 downregulation contributes to GC growth and affects patient prognosis (47-50). GAS5 is downregulated, while miR-222 is upregulated in GC cells (51). In addition, GAS5 acts as a sponge via direct binding with and downregulation of miR-222 (51). Notably, mechanistic assays showed that the GAS5/miR-222 axis regulates GC cell proliferation via PTEN/Akt/mTOR signaling (51). Consequently, GAS5/miR-222/PTEN/Akt/mTOR signaling may be a potential target for gastric cancer treatment (51). GAS5 expression levels in gastric cancer tissues are markedly reduced compared with those of normal tissues, and decreased GAS5 expression levels are associated with increased tumor size and advanced clinical stage in gastric cancer (47). GAS5 induces GC cell growth arrest by suppressing the $\mathrm{G}_{1}-\mathrm{S}$ transition (47). GAS5 effects may occur via p21 upregulation and CDK6 suppression (47). The aforementioned results indicate that GAS5 serves a role in GC etiology, suggesting that GAS5 may become a novel therapeutic target in gastric cancer. 
Table I. Functional characterization of growth arrest-specific transcript 5 in various tumors.

\begin{tabular}{|c|c|c|c|c|c|}
\hline Tumor type & Expression & Functional role & Associated gene & Role & Refs. \\
\hline Breast cancer & Downregulation & $\begin{array}{l}\text { Chemoresistance, } \\
\text { autophagy }\end{array}$ & $\begin{array}{l}\text { miR-23a, } \\
\text { PTEN, } \\
\text { miR-21 }\end{array}$ & Tumor suppressor & $31-33$ \\
\hline Prostate cancer & Downregulation & $\begin{array}{l}\text { Chemoresistance, } \\
\text { apoptosis, } \\
\text { metastasis }\end{array}$ & - & Tumor suppressor & $35-39$ \\
\hline Colorectal cancer & Downregulation & $\begin{array}{l}\text { Proliferation, } \\
\text { apoptosis, } \\
\text { metastasis }\end{array}$ & $\begin{array}{l}\text { miR-182-5p, } \\
\text { FOXO3a }\end{array}$ & Tumor suppressor & 41,42 \\
\hline Gastric cancer & Downregulation & Proliferation & $\begin{array}{l}\text { miR-222, } \\
\text { CDK6, } \\
\text { PTEN/Akt/m } \\
\text { TOR } \\
\text { pathway, p21 }\end{array}$ & Tumor suppressor & 47,51 \\
\hline Melanoma & Downregulation & $\begin{array}{l}\text { Migration, } \\
\text { invasion, apoptosis }\end{array}$ & $\begin{array}{l}\text { MMP2 } \\
\text { G6PD }\end{array}$ & Tumor suppressor & 54,55 \\
\hline $\begin{array}{l}\text { Esophageal } \\
\text { squamous cell } \\
\text { carcinoma }\end{array}$ & Downregulation & $\begin{array}{l}\text { Proliferation, } \\
\text { migration, invasion }\end{array}$ & $\begin{array}{l}\text { PI3K/Akt/ } \\
\text { mTOR pathway, } \\
\text { miR-196a }\end{array}$ & Tumor suppressor & 58,59 \\
\hline $\begin{array}{l}\text { Non-small } \\
\text { cell lung cancer }\end{array}$ & Downregulation & $\begin{array}{l}\text { Metastasis, } \\
\text { apoptosis }\end{array}$ & - & Tumor suppressor & 60,61 \\
\hline Ovarian cancer & Downregulation & $\begin{array}{l}\text { Proliferation, } \\
\text { apoptosis }\end{array}$ & miR-196a-5p & Tumor suppressor & 63,64 \\
\hline Cervical cancer & Downregulation & $\begin{array}{l}\text { Proliferation, } \\
\text { invasion, } \\
\text { migration, } \\
\text { chemoresistance }\end{array}$ & $\begin{array}{l}\text { Akt, } \\
\text { miR-106b, } \\
\text { IER3 }\end{array}$ & Tumor suppressor & $66-69$ \\
\hline Gliomas & Downregulation & $\begin{array}{l}\text { Proliferation, } \\
\text { invasion, } \\
\text { migration }\end{array}$ & $\begin{array}{l}\text { miR-222, } \\
\text { miR-18a-5p }\end{array}$ & Tumor suppressor & 73,74 \\
\hline Osteosarcoma & Downregulation & $\begin{array}{l}\text { Proliferation, } \\
\text { migration, EMT }\end{array}$ & $\begin{array}{l}\text { miR-221, } \\
\text { ARHI, } \\
\text { miR-203a }\end{array}$ & Tumor suppressor & 75,76 \\
\hline Pancreatic cancer & Downregulation & $\begin{array}{l}\text { Proliferation, } \\
\text { migration, EMT }\end{array}$ & $\begin{array}{l}\text { SOCS3, } \\
\text { CDK6, } \\
\text { miR-221 }\end{array}$ & Tumor suppressor & 77,78 \\
\hline Bladder cancer & Downregulation & $\begin{array}{l}\text { Proliferation, } \\
\text { apoptosis }\end{array}$ & $\begin{array}{l}\text { EZH2, } \\
\text { CDK6, E2F4 }\end{array}$ & Tumor suppressor & 79,80 \\
\hline $\begin{array}{l}\text { Renal cell } \\
\text { carcinoma }\end{array}$ & Downregulation & $\begin{array}{l}\text { Proliferation, } \\
\text { migration, invasion }\end{array}$ & miR-223 & Tumor suppressor & 82 \\
\hline $\begin{array}{l}\text { Papillary thyroid } \\
\text { carcinoma }\end{array}$ & Downregulation & Proliferation & $\operatorname{miR}-222-3 p$ & Tumor suppressor & 83 \\
\hline Neuroblastoma & Downregulation & $\begin{array}{l}\text { Proliferation, } \\
\text { apoptosis }\end{array}$ & $\begin{array}{l}\text { p53, BRCA1, } \\
\text { GADD45A }\end{array}$ & Tumor suppressor & 84 \\
\hline $\begin{array}{l}\text { Endometrial } \\
\text { cancer }\end{array}$ & Downregulation & Apoptosis & $\begin{array}{l}\text { PTEN, } \\
\text { miR-103 }\end{array}$ & Tumor suppressor & 85 \\
\hline $\begin{array}{l}\text { Hepatocellular } \\
\text { carcinoma }\end{array}$ & Downregulation & $\begin{array}{l}\text { Proliferation, } \\
\text { migration, invasion }\end{array}$ & $\begin{array}{l}\text { miR-21, } \\
\text { PDCD4, } \\
\text { PTEN }\end{array}$ & Tumor suppressor & 87 \\
\hline
\end{tabular}

EMT, epithelial-mesenchymal transition; miR, microRNA.

Melanoma. Melanoma is an aggressive disease with an increasing incidence rate and is the leading cause of skin cancer-associated death in the United States (52). Although targeted therapy and immunotherapy have markedly 
Table II. Clinical significance of growth arrest-specific transcript 5 in various types of tumor.

\begin{tabular}{lll}
\hline Cancer type & \multicolumn{1}{c}{ Clinicopathological features } & Refs. \\
\hline Breast cancer & Tumor size, lymph node metastasis & $(31)$ \\
Colorectal cancer & Advanced clinical stage, lymph node & $(41)$ \\
metastasis & Poor prognosis, tumor size, advanced \\
clinical stage & $(47-50)$ \\
Non-small cell lung cancer & Tumor size, lymph node metastasis \\
Ovarian cancer & $\begin{array}{l}\text { Tumor size, advanced FIGO stage (III-IV), } \\
\text { poor prognosis }\end{array}$ & $(61)$ \\
Bladder cancer & Advanced clinical stage & $(62,63)$ \\
Hepatocellular carcinoma & Poor prognosis & $(79)$ \\
\hline
\end{tabular}

TNM, Tumor-Node-Metastasis; FIGO, International Federation of Gynecology and Obstetrics.

improved melanoma treatment and patient quality of life, currently there are few suitable drugs for the treatment of this disease (53). Therefore, further assessment of the metastatic progression in melanoma is needed to develop novel targeted therapeutics. Overexpression of GAS5 inhibits the malignant potential of melanoma SK-Mel-110 cells, partly by reducing MMP2 expression levels and activity (54). One previous study showed that GAS5 has physical effects, with G6PD expression reducing GAS5-associated cell apoptosis, inducing $\mathrm{G}_{1} / \mathrm{S}$ progression and altering reactive oxygen species levels in melanoma cells (55). These findings indicate that abnormal downregulation of GAS5 has a function in melanoma development.

Esophageal squamous cell carcinoma (ESCC). Esophageal cancer (EC) ranks 8th and 6th in incidence and mortality, respectively, among malignancies worldwide, and the majority of EC cases are ESCC $(56,57)$. Functionally, GAS5 overexpression inhibits ESCC cell proliferation and reduces the migratory and invasive abilities of ESCC cells by inactivating the PI3K/Akt/mTOR signaling pathway (58). In addition, GAS5 represents a miR-196a target and functions as a tumor suppressor gene in ESCC (59). Furthermore, GAS5 is often downregulated in ESCC and associated with clinical stage. The decrease in GAS5 expression levels in ESCC is associated with miR-196a upregulation (59). GAS5 suppresses tumor growth in ESCC both in cell culture and animal models (59). Finally, miR-196a may downregulate GAS5 via the RISC (59). The aforementioned findings suggest that GAS5 downregulation contributes to ESCC development.

Non-small cell lung cancer (NSCLC). GAS5 expression levels are also associated with malignancy and metastasis in patients with NSCLC. Indeed, GAS5 upregulation leads to growth stagnation in NSCLC cells and promotes cell apoptosis both in cell and animal models (60). Meanwhile, GAS5 downregulation promotes tumor cell growth (60). In 72 NSCLC specimens, GAS5 expression levels were downregulated compared with those in adjacent noncancerous lung tissue samples. Downregulated GAS5 expression levels were associated with tumor size and lymph node metastasis (61). The aforementioned findings indicate that GAS5 may also serve as an NSCLC biomarker.

Ovarian cancer. Low GAS5 expression levels and high miR-196a-5p expression levels are associated with increased tumor volume and more advanced International Federation of Gynecology and Obstetrics stage (III-IV) in ovarian cancer $(62,63)$. GAS5 downregulation is associated with increased survival, faster proliferation and reduced apoptosis rate of ovarian cancer cells, as well as increased tumor volume in rats (63). GAS5 can directly bind to and regulate miR-196a-5p. miR-196a-5p expression is elevated in ovarian cancer tissues and cell lines, suggesting that it could promote ovarian cancer (63). High GAS5 expression levels promote apoptosis in ovarian cancer cells (64). These results indicate that reduced GAS5 expression levels may be an indicator of poor prognosis in ovarian cancer and a plausible target for diagnosing and treating this malignancy.

Cervical cancer $(C C)$. GAS5 is downregulated in multiple malignancies, including CC. A previous study showed that GAS5-knockdown can promote malignancy in CC cells (65), while GAS5 overexpression increases the resistance of CC cells to cisplatin by modulating Akt phosphorylation (66). In addition, according to bioinformatic prediction, GAS5 is a molecular sponge of miR-106b; reduced GAS5 and elevated miR-106b expression levels were found in clinical CC tissue samples from patients insensitive to radiotherapy $(67,68)$. GAS5 regulates IER3 via miR-106b, and could enhance radiosensitivity in CC cells by suppressing miR-106b both in cell and animal models (69). Together, these findings suggest that GAS5 may be a novel plausible target for cervical cancer treatment.

Glioma. In comparison with non-cancerous cerebral tissues, gliomas show reduced GAS5 expression levels (70), which are associated with a longer survival time (71). It has been demonstrated that GAS5 expression levels are elevated under stress in glioma cells induced by DNA damage (72). Previously, Zhao et al (73) confirmed GAS5 exerts antitumor effects in glioma cells via direct targeting of miR-222. 


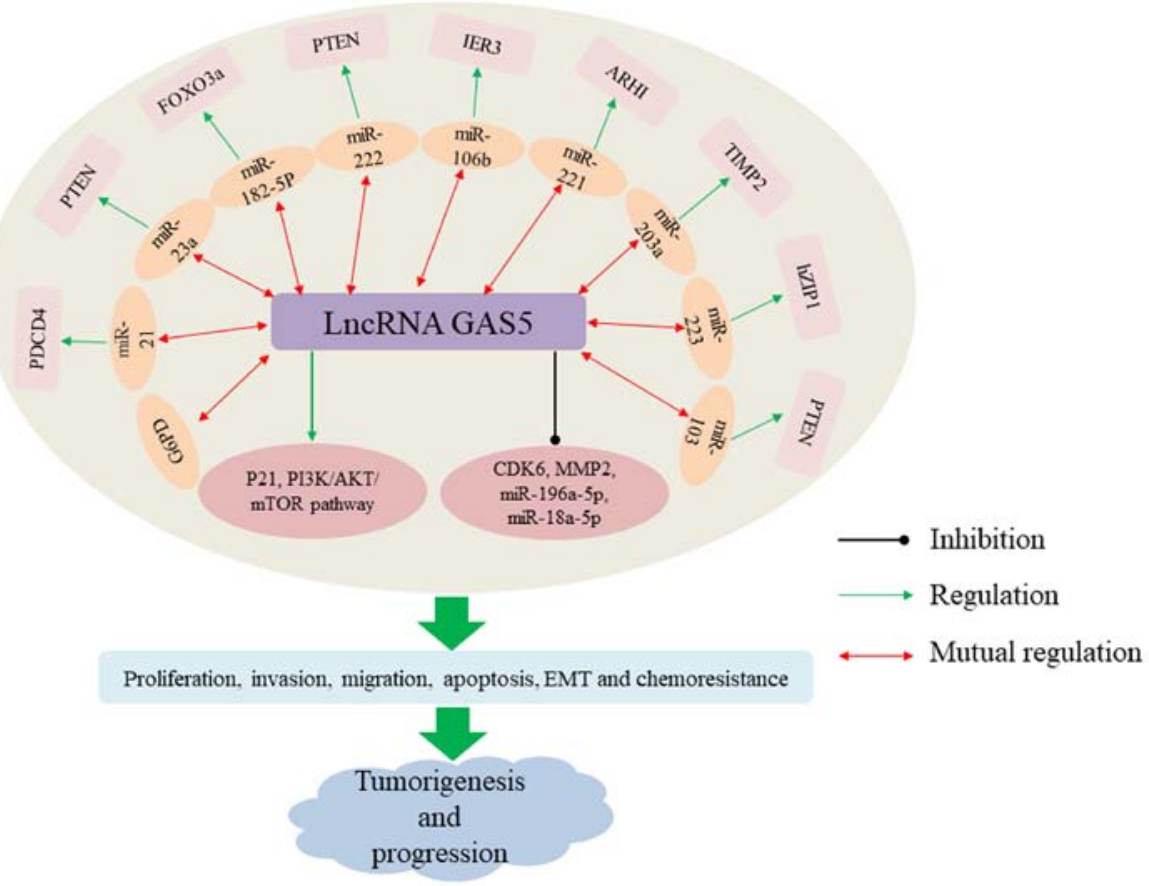

Figure 1. The regulatory mechanisms of GAS5 in human cancers. ARHI, A Ras homologue member I; CDK6, cyclin dependent kinase 6; EMT, epithelial-mesenchymal transition; FOXO3a, forkhead box O3; G6PD, glucose-6-phosphate dehydrogenase; GAS5, growth arrest-specific transcript 5; hZIP1, human ZRT, IRT-like protein 1; IER3, immediate early response gene3; MMP2, matrix metalloproteinase 2; mTOR: mammalian target of rapamycin; PDCD4, programed cell death 4; PI3K, phosphoinositide 3-kinase; PTEN, phosphate and tension homolog; TIMP2, tissue inhibitor of metalloproteinases-2.

GAS5 inhibits glioma cell proliferation both in cell and animal models, as well as cell migration and invasion. In addition, GAS5 downregulates miR-18a-5p, which in turn reduces GAS5 expression levels (74). It has also been found that GAS5 influences the biological properties of glioma cells by suppressing miR-18a-5p, thereby altering neogenin expression (74). These data indicate that GAS5 may present a novel therapeutic target for glioma treatment.

Osteosarcoma. Elevated GAS5 expression levels suppress proliferation, migration and epithelial mesenchymal transformation (EMT) in osteosarcoma cells (75). GAS5 shows direct binding to miR-221, decreasing the expression levels of miR-221 and upregulating ARHI. Additionally, a role for GAS5 in reducing tumor growth in osteosarcoma has been demonstrated in vivo (75). Competing with miR-221, GAS5 suppresses growth in osteosarcoma cells via miR-221/ARHI signaling (75). GAS5 may represent a tumor suppressor in osteosarcoma, isolating miR-203a from TIMP2 through sponge action (76). These findings suggest that abnormal GAS5 downregulation may promote tumor growth via miR-221/ARHI signaling.

Pancreatic cancer $(P C)$. Previous studies have shown that GAS5 expression in PC is markedly decreased compared with that in non-cancerous pancreatic ductal cells. Overexpression of GAS5 enhances the expression of cytokine signal transduction factor 3 and inhibits proliferation, migration, gemcitabine resistance, stem-like characteristics and EMT in PC cells via direct binding to and downregulation of miR-221 (77). Furthermore, the expression levels of CDK6 are reduced by GAS5 in cell and animal models (77). CDK6 downregula- tion partly decreases GAS5-siRNA-associated tumor cell growth (78). The aforementioned results indicate that decreased GAS5 expression levels may promote growth and metastasis in PC by negatively regulating CDK6.

Bladder cancer. GAS5 expression levels in bladder cancer cells and clinical samples are low and inversely associated with disease stage, and elevated GAS5 expression levels inhibit bladder cancer cell proliferation (79). By interacting with the transcription factor E2F transcription factor 4, GAS5 downregulates EZH2 at the mRNA level and promotes apoptosis in bladder cancer cells, and GAS5 serves a role in GA-associated apoptosis in bladder cancer (79). Additionally, GAS5 exerts its effects in part via CDK6 regulation, as GAS5 downregulation increases CDK6 mRNA and protein expression levels, and since inhibition of GAS5 leads to significantly decreased $\mathrm{G}_{0} / \mathrm{G}_{1}$ phase and markedly increased $S$ phase in bladder cancer cells (80). These data suggest that GAS5 may represent a novel target for treating bladder cancer.

Renal cell carcinoma (RCC). In comparison with non-cancerous cells, RCC cells show significantly downregulated GAS5 expression levels (81). GAS5 overexpression decreases the level of malignancy in RCC cells (82). A study showed that GAS5 serves as a competing endogenous RNA for miR-223; the inhibition of GAS5 attenuates the activity of miR-223 inhibitor on cell growth, apoptosis and invasion. Additionally, GAS5 downregulation facilitates tumor growth in vivo, which is abolished by hZIP1 overexpression (82). The aforementioned data indicates that GAS5 may present a novel target for RCC treatment. 
Papillary thyroid carcinoma (PTC). GAS5 expression levels are markedly reduced in PTC tissue samples and cells. GAS5 overexpression suppresses PTC growth in cell and animal models. In addition, GAS5 is considered a target of miR-222-3p, which is abnormally elevated in PTC cells (83). These data indicate that GAS5 may present a novel target for treating PTC.

Neuroblastoma. GAS5 is highly expressed in both MYCN-amplified and non-amplified neuroblastoma cells, and GAS5 downregulation leads to elevated cell proliferation and reduced apoptosis and cell cycle arrest in neuroblastoma cells (84). In addition, deletion of GAS5 upregulates p53, BRCA1 protein and growth arrest and DNA-damage-inducible protein $\alpha$, which seem to simultaneously regulate cell cycle arrest (84). These data indicate that abnormal GAS5 downregulation may promote neuroblastoma progression by inducing cell cycle arrest.

Endometrial cancer. GAS5 is downregulated and induces apoptosis in endometrial cancer cells (85). When endometrial cancer cells overexpress GAS5, PTEN is upregulated (85). Furthermore, bioinformatics prediction revealed that GAS5 could bind to miR-103 and significantly upregulate PTEN to induce apoptosis via miR-103 downregulation (85). Thus, GAS5 may be a regulator of endometrial cancer pathogenesis.

Hepatocellular carcinoma (HCC). The expression levels of GAS5 in HCC tissues is decreased compared with normal adjacent tissues, suggesting poor prognosis of HCC patients (86). Additionally, GAS5 suppresses hepatoma cell growth in association with vimentin regulation (86). Another study showed that GAS5 serves an anticancer role in HCC by negatively regulating miR-21 and its target protein PDCD4 and PTEN to alter the migratory and invasive features of HCC cells (87). In addition, Tao et al (88) reported that GAS5 may act as a proto-oncogene in HCC. Therefore, GAS5 may potentially be a novel target for HCC treatment.

\section{Conclusions}

GAS5 is downregulated in a number of human malignancies. GAS5 can induce apoptosis and inhibit the proliferative and metastatic properties of tumors. The exact molecular mechanisms by which GAS5 affects cancer development remain unclear. GAS5 may serve a role in tumorigenesis by regulating multiple tumor-associated molecules. Tumor inhibition by GAS5 has been described for numerous malignancies, such as breast cancer, prostate cancer, CRC, stomach cancer, melanoma, ESCC, NSCLC, ovarian cancer, cervical cancer, gliomas, osteosarcoma, pancreatic cancer, bladder cancer, RCC, PTC, neuroblastoma, endometrial cancer and HCC, indicating a role for this IncRNA as a tumor suppressor. In this review, the potential of GAS5 in diagnosing and treating different cancer types, and its potential clinical application, were summarized, pointing to a new direction for GAS5 research.

\section{Acknowledgements}

Not applicable.

\section{Funding}

The present study was funded by The Provincial Natural Science Foundation of Hunan (grant nos. 2019JJ50500 and 2017JJ2226), The Hunan Provincial Key Laboratory of Tumor Microenvironment Responsive Drug Research [Hunan Provincial Science and Technology Department Document (grant number 2019-56)], The Scientific Research Fund of Hunan Provincial Education Department (grant no. 17C1402), The Hunan Province Cooperative Innovation Center for Molecular Target New Drug Study (grant no. 2014-405) and The Undergraduate Research-based Learning and Innovative Experimental Program of University of South China (grant nos. 2017XJYZ040 and 2018XJXZ348).

\section{Availability of data and materials}

Not applicable.

\section{Authors' contributions}

XY wrote the original draft. The manuscript was revised by ZX, $\mathrm{XL}$ and RG. The authors read and approved the final manuscript.

\section{Ethics approval and consent to participate}

Not applicable.

Patient consent for publication

Not applicable.

\section{Competing interests}

The authors declare that they have no competing interests.

\section{References}

1. Bray F, Ferlay J, Soerjomataram I, Siegel RL, Torre LA and Jemal A: Global cancer statistics 2018: GLOBOCAN estimates of incidence and mortality worldwide for 36 cancers in 185 countries. CA Cancer J Clin 68: 394-424, 2018.

2. Zugazagoitia J, Guedes C, Ponce S, Ferrer I, Molina-Pinelo S and Paz-Ares L: Current challenges in cancer treatment. Clin Ther 38: 1551-1566, 2016.

3. Van Cutsem E, Sagaert X, Topal B, Haustermans K and Prenen H: Gastric cancer. Lancet 388: 2654-2664, 2016.

4. Ma Y, Yang Y, Wang F, Moyer MP, Wei Q, Zhang P, Yang Z, Liu W, Zhang $\mathrm{H}$, Chen $\mathrm{N}$, et al: Long non-coding RNA CCAL regulates colorectal cancer progression by activating Wnt $/ \beta$ catenin signalling pathway via suppression of activator protein 2 $\alpha$. Gut 65: 1494-1504, 2016.

5. Ruan X, Li P, Cangelosi A, Yang L and Cao H: A long non-coding RNA, lncLGR, regulates hepatic glucokinase expression and glycogen storage during fasting. Cell Rep 14: 1867-1875, 2016.

6. Veneziano D, Nigita G and Ferro A: Computational approaches for the analysis of ncRNA through deep sequencing techniques. Front Bioeng Biotechnol 3: 77, 2015.

7. Theis M, Paszkowski-Rogacz M, Weisswange I, Chakraborty D and Buchholz F: Targeting human long noncoding transcripts by endoribonucleaseprepared sirnas. J Biomol Screen 20: 1018-1026, 2015.

8. Chen X and Yan GY: Novel human lncRNA-disease association inference based on lncRNA expression profiles. Bioinformatics 29: 2617-2624, 2013.

9. Chen X, Yan CC, Luo C, Ji W, Zhang Y and Dai Q: Constructing lncRNA functional similarity network based on lncRNA-disease associations and disease semantic similarity. Sci Rep 5: 11338, 2015. 
10. Mercer TR, Dinger ME and Mattick JS: Long non-coding RNAs: Insights into functions. Nat Rev Genet 10: 155-159, 2009.

11. Fatica A and Bozzoni I: Long non-coding RNAs: New players in cell differentiation and development. Nat Rev Genet 15: 7-21, 2014.

12. Schmitt AM and Chang HY: Long noncoding rnas in cancer pathways. Cancer Cell 29: 452-463, 2016.

13. Huarte M: The emerging role of IncRNAs in cancer. Nat Med 21: 1253-1261, 2015.

14. Zhang S, Chen S, Yang G, Gu F, Li M, Zhong B, Hu J, Hoffman A and Chen M: Long noncoding RNA HOTAIR as an independent prognostic marker in cancer: A meta-analysis. PLoS One 9: e105538, 2014.

15. Xue Y, Teng YQ, Zhou JD and Rui YJ: Prognostic value of long non-coding RNA MALAT1 in various carcinomas: Evidence from nine studies. Tumour Biol 37: 1211-1215, 2016.

16. Mourtada-Maarabouni M, Pickard MR, Hedge VL, Farzaneh F and Williams GT: GAS5, a non-protein-coding RNA, controls apoptosis and is downregulated in breast cancer. Oncogene 28: 195-208, 2009.

17. Sun M, Jin FY, Xia R, Kong R, Li JH, Xu TP, Liu YW, Zhang EB, Liu XH and De W: Decreased expression of long non-coding RNA GAS5 indicates a poor prognosis and promotes cell proliferation in gastric cancer. BMC Cancer 14: 319, 2014.

18. Pickard MR, Mourtada-Maarabouni M and Williams GT: Long non-coding RNA GAS5 regulates apoptosis in prostate cancer cell lines. Biochim Biophys Acta 1832: 1613-1623, 2013.

19. Coccia EM, Cicala C, Charlesworth A, Ciccarelli C, Rossi GB, Philipson L and Sorrentino V: Regulation and expression of a growth arrest-specific gene (gas5) during growth, differentiation, and development. Mol Cell Biol 12: 3514-3521, 1992.

20. Fleming JV, Fontanier N, Harries DN and Rees WD: The growth arrest genes gas5, gas6, and CHOP-10 (gadd153) are expressed in the mouse preimplantation embryo. Mol Reprod Dev 48: 310-316, 1997.

21. Schneider C, King RM and Philipson L: Genes specifically expressed at growth arrest of mammalian cells. Cell 54: 787-793, 1988.

22. Smith CM and Steitz JA: Classification of gas5 as a multi-small-nucleolar-RNA (snoRNA) host gene and a member of the 5'-terminal oligopyrimidine gene family reveals common features of snoRNA host genes. Mol Cell Biol 18: 6897-6909, 1998.

23. Ma C, Shi X, Zhu Q, Li Q, Liu Y, Yao Y and Song Y: The growth arrest-specific transcript 5 (GAS5): A pivotal tumor suppressor long non-coding RNA in human cancers. Tumour Biol 37 $1437-1444,2016$

24. Shi X, Sun M, Liu H, Yao Y, Kong R, Chen F and Song Y: A critical role for the long non-coding RNA GAS5 in proliferation and apoptosis in non-small-cell lung cancer. Mol Carcinog 54 (Suppl 1): E1-E12, 2015

25. Mourtada-Maarabouni M, Hedge VL, Kirkham L, Farzaneh F and Williams GT: Growth arrest in human T-cells is controlled by the non-coding RNA growth-arrest-specific transcript 5 (GAS5). J Cell Sci 121: 939-946, 2008.

26. Sun M, Jin FY, Xia R, Kong R, Li JH, Xu TP, Liu YW, Zhang EB, Liu XH and De W: Decreased expression of long non-coding RNA GAS5 indicates a poor prognosis and promotes cell proliferation in gastric cancer. BMC Cancer 14: 319, 2014

27. Yin D, He X,Zhang E, Kong R, De W and Zhang Z: Long non-coding RNA GAS5 affects cell proliferation and predicts a poor prognosis in patients with colorectal cancer. Med Oncol 31: 253, 2014.

28. Kino T, Hurt DE, Ichijo T, Nader $\mathrm{N}$ and Chrousos GP: Noncoding RNA gas 5 is a growth arrest- and starvation-associated repressor of the glucocorticoid receptor. Sci Signal 3: ra8, 2010

29. Liu Z, Wang W, Jiang J, Bao E, Xu D, Zeng Y, Tao L and Qiu J: Downregulation of GAS5 promotes bladder cancer cell proliferation, partly by regulating CDK6. PLoS One 8: e73991, 2013.

30. Lu X, Fang Y, Wang Z, Xie J, Zhan Q, Deng X, Chen H, Jin J, Peng $\mathrm{C}, \mathrm{Li} \mathrm{H}$, et al: Downregulation of gas5 increases pancreatic cancer cell proliferation by regulating CDK6. Cell Tissue Res 354: 891-896, 2013

31. Gu J, Wang Y, Wang X, Zhou D, Wang X, Zhou M and He Z: Effect of the lncRNA GAS5-miR-23a-ATG3 axis in regulating autophagy in patients with breast cancer. Cell Physiol Biochem 48: 194-207, 2018.

32. Li W, Zhai L, Wang H, Liu C, Zhang J, Chen W and Wei Q: Downregulation of LncRNA GAS5 causes trastuzumab resistance in breast cancer. Oncotarget 7: 27778-27786, 2016.
33. Zhang Z, Zhu Z, Watabe K, Zhang X, Bai C, Xu M, Wu F and Mo YY: Negative regulation of IncRNA GAS5 by miR-21. Cell Death Differ 20: 1558-1568, 2013.

34. Jemal A, Bray F, Center MM, Ferlay J, Ward E and Forman D: Global cancer statistics. CA Cancer J Clin 61: 69-90, 2011

35. Pickard MR, Mourtada-Maarabouni M and Williams GT: Long non-coding RNA GAS5 regulates apoptosis in prostate cancer cell lines. Biochim Biophys Acta 1832: 1613-1623, 2013.

36. Luo G, Liu D, Huang C, Wang M, Xiao X, Zeng F, Wang L and Jiang G: LncRNA GAS5 inhibits cellular proliferation by targeting P27Kip1. Mol Cancer Res 15: 789-799, 2017.

37. Xie X, Dai J, Huang X, Fang C and He W: MicroRNA-145 inhibits proliferation and induces apoptosis in human prostate carcinoma by upregulating long non-coding RNA GAS5. Oncol Lett 18: 1043-1048, 2019.

38. Abbah SA, Lam CX, Ramruttun AK, Goh JC and Wong HK: Fusion performance of low-dose recombinant human bone morphogenetic protein 2 and bone marrow-derived multipotent stromal cells in biodegradable scaffolds: A comparative study in a large animal model of anterior lumbar interbody fusion. Spine 36: 1752-1759, 2011.

39. Zhang Y, Su X, Kong Z, Fu F, Zhang P, Wang D, Wu H, Wan X and Li Y: An androgen reduced transcript of LncRNA GAS5 promoted prostate cancer proliferation. PLoS One 12: e0182305, 2017.

40. Siegel RL, Miller KD and Jemal A: Cancer statistics, 2018. CA Cancer J Clin 68: 7-30, 2018

41. Cheng K, Zhao Z, Wang G, Wang J and Zhu W: IncRNA GAS5 inhibits colorectal cancer cell proliferation via the miR182-5p/FOXO3a axis. Oncol Rep 40: 2371-2380, 2018

42. Yang Y, Shen Z, Yan Y, Wang B, Zhang J, Shen C, Li T, Ye C, Gao Z, Peng G, et al: Long non-coding RNA GAS5 inhibits cell proliferation, induces $\mathrm{G} 0 / \mathrm{G} 1$ arrest and apoptosis, and functions as a prognostic marker in colorectal cancer. Oncol Lett 13: 3151-3158, 2017

43. Miyahara R, Niwa Y, Matsuura T, Maeda O, Ando T, Ohmiya N, Itoh A, Hirooka $\mathrm{Y}$ and Goto $\mathrm{H}$ : Prevalence and prognosis of gastric cancer detected by screening in a large Japanese population: Data from a single institute over 30 years. J Gastroenterol Hepatol 22: 1435-1442, 2007.

44. Zabaleta J: Multifactorial etiology of gastric cancer. Methods Mol Biol 863: 411-435, 2012.

45. Vogelaar IP, van der Post RS, Bisseling TM, van Krieken JHJ, Ligtenberg MJ and Hoogerbrugge N: Familial gastric cancer: Detection of a hereditary cause helps to understand its etiology. Hered Cancer Clin Pract 10: 18, 2012.

46. Correa P and Schneider BG: Etiology of gastric cancer: What is new? Cancer Epidemiol Biomarkers Prev 14: 1865-1868, 2005 .

47. Guo X, Deng K, Wang H, Xia J, Shan T, Liang Z, Yao L and Jin S: GAS5 Inhibits gastric cancer cell proliferation partly by modulating CDK6. Oncol Res Treat 38: 362-366, 2015.

48. Liu X, Jiao T, Wang Y, Su W, Tang Z and Han C: Long non-coding RNA GAS5 acts as a molecular sponge to regulate miR-23a in gastric cancer. Minerva Med: Nov 9, 2016 (Epub ahead of print).

49. Sun M, Jin FY, Xia R, Kong R, Li JH, Xu TP, Liu YW, Zhang EB, Liu XH and De W: Decreased expression of long non-coding RNA GAS5 indicates a poor prognosis and promotes cell proliferation in gastric cancer. BMC Cancer 14: 319, 2014

50. Zhang N, Wang AY, Wang XK, Sun XM and Xue HZ: GAS5 is downregulated in gastric cancer cells by promoter hypermethylation and regulates adriamycin sensitivity. Eur Rev Med Pharmacol Sci 20: 3199-3205, 2016.

51. LiY,Gu Jand LuH:TheGAS5/miR-222 axis regulates proliferation of gastric cancer cells through the PTEN/ Akt/ mTOR pathway. Dig Dis Sci 62: 3426-3437, 2017.

52. Siegel RL, Miller KD and Jemal A: Cancer statistics, 2015. CA Cancer J Clin 65: 5-29, 2015.

53. Sun J, Carr MJ and Khushalani NI: Principles of targeted therapy for melanoma. Surg Clin North Am 100: 175-188, 2020.

54. Chen L, Yang H, Xiao Y, Tang X, Li Y, Han Q, Fu J, Yang Y and Zhu Y: Lentiviral-mediated overexpression of long non-coding RNA GAS5 reduces invasion by mediating MMP2 expression and activity in human melanoma cells. Int J Oncol 48: 1509-1518, 2016.

55. Chen L, Yang H, Yi Z, Jiang L, Li Y, Han Q, Yang Y, Zhang Q, Yang Z, Kuang Y, et al: LncRNA GAS5 regulates redox balance and dysregulates the cell cycle and apoptosis in malignant melanoma cells. J Cancer Res Clin Oncol 145: 637-652, 2019. 
56. Zhang Y: Epidemiology of esophageal cancer. World J Gastroenterol 19: 5598-5606, 2013.

57. Arnold M, Soerjomataram I, Ferlay J and Forman D: Global incidence of oesophageal cancer by histological subtype in 2012. Gut 64: 381-387, 2015.

58. Wang G, Sun J,ZhaoH and LiH:Long non-coding RNA(lncRNA) Growth Arrest Specific 5 (GAS5) suppresses esophageal squamous cell carcinoma cell proliferation and migration by inactivating phosphatidylinositol 3-kinase (PI3K)/AKT Mammalian Target of Rapamycin (mTOR) signaling pathway. Med Sci Monit 24: 7689-7696, 2018.

59. Wang K, Li J, Xiong G, He G, Guan X, Yang K and Bai Y: Negative regulation of lncRNA GAS5 by miR-196a inhibits esophageal squamous cell carcinoma growth. Biochem Biophys Res Commun 495: 1151-1157, 2018.

60. Mei Y, Si J, Wang Y, Huang Z, Zhu H, Feng S, Wu X and Wu L: Long non-coding RNA GAS5 suppresses tumorigenesis by inhibiting miR-23a expression in non-small cell lung cancer. Oncol Res 25: 1027-1037, 2017.

61. Shi X, Sun M, Liu H, Yao Y, Kong R, Chen F and Song Y: A critical role for the long non-coding RNA GAS5 in proliferation and apoptosis in non-small-cell lung cancer. Mol Carcinog 54 (Suppl 1): E1-E12, 2015.

62. McComas KN, Torgeson AM, Ager BJ, Hellekson C, Burt LM Maurer KA, Werner TL and Gaffney DK: The variable impact of positive lymph nodes in cervical cancer: Implications of the new FIGO staging system. Gynecol Oncol 156: 85-92, 2020.

63. Zhao H, Yu H, Zheng J, Ning N, Tang F, Yang Y and Wang Y: Lowly-expressed lncRNA GAS5 facilitates progression of ovarian cancer through targeting miR-196-5p and thereby regulating HOXA5. Gynecol Oncol 151: 345-355, 2018.

64. Gao J, Liu M, Zou Y, Mao M, Shen T, Zhang C, Song S, Sun $\mathrm{M}$, Zhang S, Wang B, et al: Long non-coding RNA growth arrest-specific transcript 5 is involved in ovarian cancer cell apoptosis through the mitochondria-mediated apoptosis pathway. Oncol Rep 34: 3212-3221, 2015.

65. Cao S, Liu W, Li F, Zhao W and Qin C: Decreased expression of lncRNA GAS5 predicts a poor prognosis in cervical cancer. Int J Clin Exp Pathol 7: 6776-6783, 2014

66. Wen Q, Liu Y, Lyu H, Xu X, Wu Q, Liu N, Yin Q, Li J and Sheng X: Long non-coding RNA GAS5, which acts as a tumor suppressor via microRNA 21, regulates cisplatin resistance expression in cervical cancer. Int J Gynecol Cancer 27: 1096-1108, 2017.

67. Ma D, Zhang YY, Guo YL, Li ZJ and Geng L: Profiling of microRNA-mRNA reveals roles of microRNAs in cervical cancer. Chin Med J (Engl) 125: 4270-4276, 2012.

68. Zheng L, Zhang Y, Liu Y, Zhou M, Lu Y, Yuan L, Zhang C, Hong M, Wang S and Li X: MiR-106b induces cell radioresistance via the PTEN/PI3K/AKT pathways and p21 in colorectal cancer. J Transl Med 13: 252, 2015

69. Gao J, Liu L, Li G, Cai M, Tan C, Han X and Han L: LncRNA GAS5 confers the radio sensitivity of cervical cancer cells via regulating miR-106b/IER3 axis. Int J Biol Macromol 126: 994-1001, 2019.

70. Zhang X, Sun S, Pu JK, Tsang AC, Lee D, Man VO, Lui WM, Wong ST and Leung GK: Long non-coding RNA expression profiles predict clinical phenotypes in glioma. Neurobiol Dis 48 $1-8,2012$

71. Zhang XQ, Sun S, Lam KF, Kiang KM, Pu JK, Ho AS, Lui WM, Fung CF, Wong TS and Leung GK: A long non-coding RNA signature in glioblastoma multiforme predicts survival. Neurobiol Dis 58: 123-131, 2013

72. Liu Q, Sun S, Yu W, Jiang J, Zhuo F, Qiu G, Xu S and Jiang X: Altered expression of long non-coding RNAs during genotoxic stress-induced cell death in human glioma cells. J Neurooncol 122: 283-292, 2015.
73. Zhao X, Wang P, Liu J, Zheng J, Liu Y, Chen J and Xue Y: Gas5 exerts tumor-suppressive functions in human glioma cells by targeting miR-222. Mol Ther 23: 1899-1911, 2015.

74. Liu Q, Yu W, Zhu S, Cheng K, Xu H, Lv Y, Long X, Ma L, Huang J, Sun S, et al: Long non-coding RNA GAS5 regulates the proliferation, migration, and invasion of glioma cells by negatively regulating miR-18a-5p. J Cell Physiol 234: 757-768, 2018.

75. YeK, Wang S, Zhang H,Han H, MaB and Nan W: Long non-coding RNA GAS5 suppresses cell growth and epithelial-mesenchymal transition in osteosarcoma by regulating the miR-221/ARHI pathway. J Cell Biochem 118: 4772-4781, 2017.

76. Wang Y and Kong D: LncRNA GAS5 represses osteosarcoma cells growth and metastasis via sponging MiR-203a. Cell Physiol Biochem 45: 844-855, 2018

77. Liu B, Wu S, Ma J, Yan S, Xiao Z, Wan L, Zhang F, Shang M and Mao A: lncRNA GAS5 reverses EMT and tumor stem cell-mediated gemcitabine resistance and metastasis by targeting miR-221/SOCS3 in pancreatic cancer. Mol Ther Nucleic Acids 13: 472-482, 2018.

78. Lu X, Fang Y, Wang Z, Xie J, Zhan Q, Deng X, Chen H, Jin J, Peng $\mathrm{C}, \mathrm{Li} \mathrm{H}$, et al: Downregulation of gas 5 increases pancreatic cancer cell proliferation by regulating CDK6. Cell Tissue Res 354: 891-896, 2013.

79. Wang M, Guo C, Wang L, Luo G, Huang C, Li Y, Liu D, Zeng F, Jiang $\mathrm{G}$ and Xiao $\mathrm{X}$ : Long non-coding RNA GAS5 promotes bladder cancer cells apoptosis through inhibiting EZH2 transcription. Cell Death Dis 9: 238, 2018.

80. Liu Z, Wang W, Jiang J, Bao E, Xu D, Zeng Y, Tao L and Qiu J: Downregulation of GAS5 promotes bladder cancer cell proliferation, partly by regulating CDK6. PLoS One 8: e73991, 2013.

81. Liu L, Pang X, Shang W, Xie H, Feng Y and Feng G: Long non-coding RNA GAS5 sensitizes renal cell carcinoma to sorafenib via miR-21/SOX5 pathway. Cell Cycle 18: 257-263, 2019.

82. Dong X, Kong C, Liu X, Bi J, Li Z, Li Z, Zhu Y and Zhang Z: GAS5 functions as a ceRNA to regulate hZIP1 expression by sponging miR-223 in clear cell renal cell carcinoma. Am J Cancer Res 8: 1414-1426, 2018.

83. Zhang XF, Ye Y and Zhao SJ: LncRNA Gas5 acts as a ceRNA to regulate PTEN expression by sponging miR-222-3p in papillary thyroid carcinoma. Oncotarget 9: 3519-3530, 2017.

84. Mazar J, Rosado A, Shelley J, Marchica J and Westmoreland TJ: The long non-coding RNA GAS5 differentially regulates cell cycle arrest and apoptosis through activation of BRCA1 and p53 in human neuroblastoma. Oncotarget 8: 6589-6607, 2017.

85. Guo C, Song WQ, Sun P, Jin L and Dai HY: LncRNA-GAS5 induces PTEN expression through inhibiting miR-103 in endometrial cancer cells. J Biomed Sci 22: 100, 2015.

86. Chang L, Li C, Lan T, Wu L, Yuan Y, Liu Q and Liu Z: Decreased expression of long non-coding RNA GAS5 indicates a poor prognosis and promotes cell proliferation and invasion in hepatocellular carcinoma by regulating vimentin. Mol Med Rep 13: 1541-1550, 2016.

87. Hu L, Ye H, Huang G, Luo F, Liu Y, Liu Y, Yang X, Shen J, Liu Q and Zhang J: Long noncoding RNA GAS5 suppresses the migration and invasion of hepatocellular carcinoma cells via miR-21. Tumour Biol 37: 2691-2702, 2016.

88. Tao R, Hu S, Wang S, Zhou X, Zhang Q, Wang C, Zhao X, Zhou W, Zhang S, Li C, et al: Association between indel polymorphism in the promoter region of lncRNA GAS5 and the risk of hepatocellular carcinoma. Carcinogenesis 36: 1136-1143, 2015.

This work is licensed under a Creative Commons Attribution-NonCommercial-NoDerivatives 4.0 International (CC BY-NC-ND 4.0) License. 